\title{
Safety and security solution for school bus through RFID and GSM technologies
}

\author{
Hasmah Mansor ${ }^{1}$, Tun Mohamad Aqil Mohamad Fadzir², Teddy Surya Gunawan ${ }^{3}$, Zuriati Janin ${ }^{4}$ \\ ${ }^{1,2,3}$ Department of Electrical and Computer Enginering, International Islamic University Malaysia, Malaysia \\ ${ }^{3}$ School of Electrical Engineering and Telecommunications, University of New South Wales, Australia \\ ${ }^{4}$ Faculty of Electrical Engineering, Universiti Teknologi MARA, Malaysia
}

\section{Article Info}

Article history:

Received Jun 3, 2019

Revised Aug 6, 2019

Accepted Aug 20, 2019

\section{Keywords:}

Arduino

GSM technology

Real time

RFID

\begin{abstract}
All children throughout the world aged 4 to 17 are going to schools every weekdays. The most common transport used by children is school bus. In many countries accross the globe, most children uses school bus services to go to school and return back home especially to working parents. Although safety of their children is always the main concern of all parents especially the young ones, they have to rely on the bus services due to time constraints during working hours. Sometimes parents need to call the bus driver to ensure their children has reached home or school. This will create inconvenience to bus driver and may lead to other unwanted consequences. Realizing the root of this problem, a school bus safety and security system has been proposed. The school bus safety and security system is a solution based on Short Messaging System that notifies parents if their children have safely arrived at home or school. RFID and GSM technologies are the main technique proposed in this project. RFID is used for several purposes; to identify the children and parents' contact number, and attendance monitoring through head count system. GSM is used as a commucation platform to inform parents' on their children's movement via SMS. Several tests have been conducted to analyse the overall performance of the developed hardware prototype. From the results, it can be concluded that the developed project is successfully identify the children based on their unique ID, send a text message through SMS to parents with required information; and additional feature of attendance checker. The hardware prototype was successfully tested for children's identification, attendance and SMS notifications to parents. As a consequence, this project could increase the safety and security solution for children travelling with school bus transportation and give parents peace of mind.
\end{abstract}

Copyright $(0) 2020$ Institute of Advanced Engineering and Science. All rights reserved.

\section{Corresponding Author:}

Hasmah Mansor,

Department of Electrical and Computer Engineering,

Internation Islamic University Malaysia, Malaysia.

Email: hasmahm@iium.edu.my

\section{INTRODUCTION}

School bus plays a vital role to provide sustainable transportation to children whose parents are working. Although safety and security of their children are very much important, they rely on the school bus services due to time constraint and other limitation. Under worrying situation, parents usually call bus driver to check on their children if the bus driver late or forgot to pick-up the children. This issue may indirectly lead to unfortunate incidents and probably increase kidnapping or other crime activities involving school students. Statistical report by national crime bureau states that in every eight minutes children go missing 
caused by kidnapping [1]. Anxiety feelings have risen among parents and solution for safety and security issues of school bus is in demand.

Research related to security system using RFID is not practically new. Tracking system of school bus using Global System for Mobile communication (GSM) module and RFID technology and has been presented by [1]. To provide tracking mechanism, RFID tag was embedded inside the student's identity card. Once scanned over the RFID reader, a notification messages was sent to the registered parents' mobile phone number using SIM-300 GSM module technology. The major problem with this approach was that the system used the older version of GPRS functionalities which work based on $2 \mathrm{G}$ and $3 \mathrm{G}$ while the world is moving towards 5G. Kindergarten Intelligence Security has been proposed by other researchers. The proposed system used microcontroller as an interface between RFID and GSM modem. The RFID tags were embedded inside the children uniform in order to provide the security monitoring [2]. In line with Industrial Revolution 4.0, the system worked based on Internet of Thing (IoT) framework. Database containing the students' information were stored in a cloud computing services. Other research related to children security system is available in [3]. In [4], GPS/GPRS/GSM Module has been used for bus tracking system through satellite navigation. Similarly, [5] has proposed Arduino Uno R3, GSM device and GPS to track the exact and accurate position of the vehicle at a location in realtime on smartphone application. In [6], the vehicle tracking system has been proposed to monitor the exact locations of the delivery vehicle used by food-related businesses. GSM and GPS technologies are always important and reliable for tracking purposes and notification messages to registered users. In the project, GSM has been proposed as medium for sending notifications to parents on their children whereabout.

Since many years, RFID has been proven to be suitable and effective for security purposes. RFID is well known with its security applications; for example control of multilevel car parking and door access control for different type of users [7, 8]. In [9], message will be sent to preset number if there are unsuccessful attempts in entering incorrect 5-digit password of digital security door, as a means of detecting unauthorised intrusion. In food industry, RFID has been proposed in halal industry for checking the halal status of food [10]. RFID tag was embedded at the food packaging and the unique ID was checked/matched with the halal database. In addition, in [11] presented the RFID technology in the project called Web-based Laboratory Attendance System (LAS). The student web-based attendance system was implementing the Serial UART RFID types to detect the unique electronic serial ID of the student card. The system was integrated with a passive card approach that has been embedded inside the student ID card. The use of cloud computing services is needed in order to record the data of the attendance system.

Other examples of RFID applications are supply-chain application, food retailing in the UK (Walmart), wine temperature tracking, library system, tracking of student movement and student attendance monitoring, to name a few [12-16]. As a summary, RFID technology is proven to be able to work for realtime tracking and security monitoring.

Realising the importance of school bus security in the form of children's safety, this project proposed a development of safety and security system that is possible to be implemented at every school busses registered in Malaysia, starting with Klang Valley area. The focus group is all school children from kindergarten to secondary who are using school bus services. This security system mainly comprises of Arduino as a microcontroller, Global System for Mobile communication (GSM) and Radio Frequency Identification (RFID) tag and reader. Besides user identification, RFID technology is used for attendace trackker; to count every entry and exit of the students from the school buses. GSM technology is used to allow the communication between transmitter (on the school bus) and the receiver (parents). The notification message is sent to the parents by using the Short Message Service (SMS) with students' detail and their whereabout.

The implementation of this project could give peace of mind to the parents who are entrusting their children traveling with the school bus, increase safety and security, reduce anxiety and possibly would create more efficient working environment. Klang Valley has been chosen as the focus area due to reliability of GSM connection and high dependency on school bus services from working parents.

\section{DESIGN OF SCHOOL BUS SECURITY SYSTEM}

This research proposed safety and security solution of school bus transportation where parents are informed about their children whereabout via SMS with attendance system. The proposed system take count at every entry and exit of students based on recognizing the unique identification information of the RFID technology. Once a student touch his/her RFID tag to the RFID reader, the system will display the student's name that has been registered on the Liquid Crystal Display (LCD). The GSM module enables parents to be informed via the SMS when their children is entering or leaving the school bus. The operation mechanism 
between the components are controlled by a microcontroller, Arduino Uno. Figure 1 illustrates how the school bus security system works.

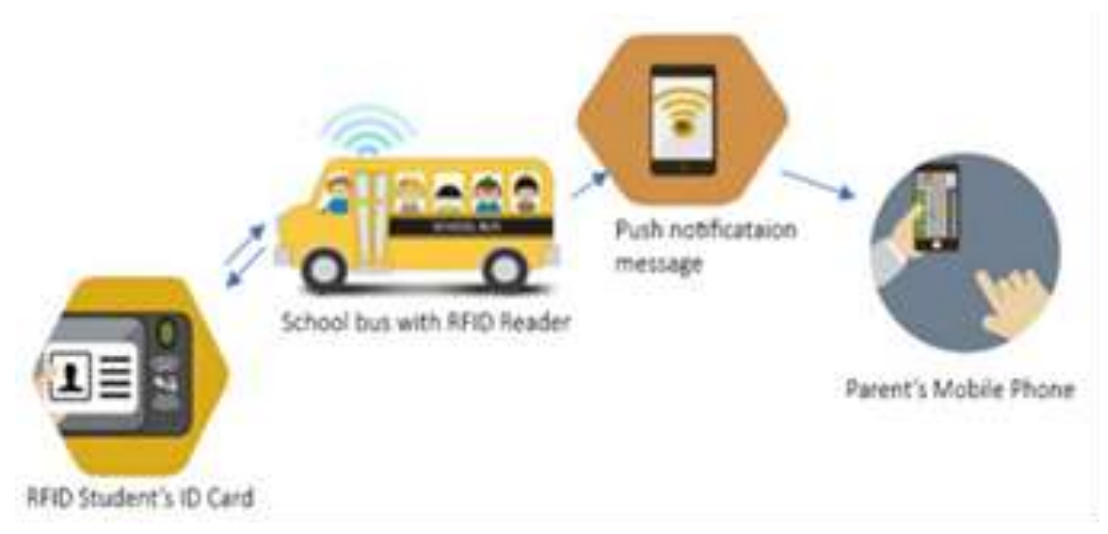

Figure 1. Proposed school bus security system

\subsection{Workflow Diagram}

First, RC-522 RFID reader is installed at school bus. Students are provided with the passive RFID tags that have been registered with unique serial identification number. RC-522 RFID reader will look for the unique identification number of the respective students and display it on the LCD. Meanwhile, GSM technology provides a response to the given data and send the notification message towards the registered parent's mobile phone number. Two different timeframes have been set (morning and evening) to indicate the student is on board from home/school or otherwise. The system will inform the parents about their children's attendance. Figure 2 shows the workflow diagram of the proposed system.

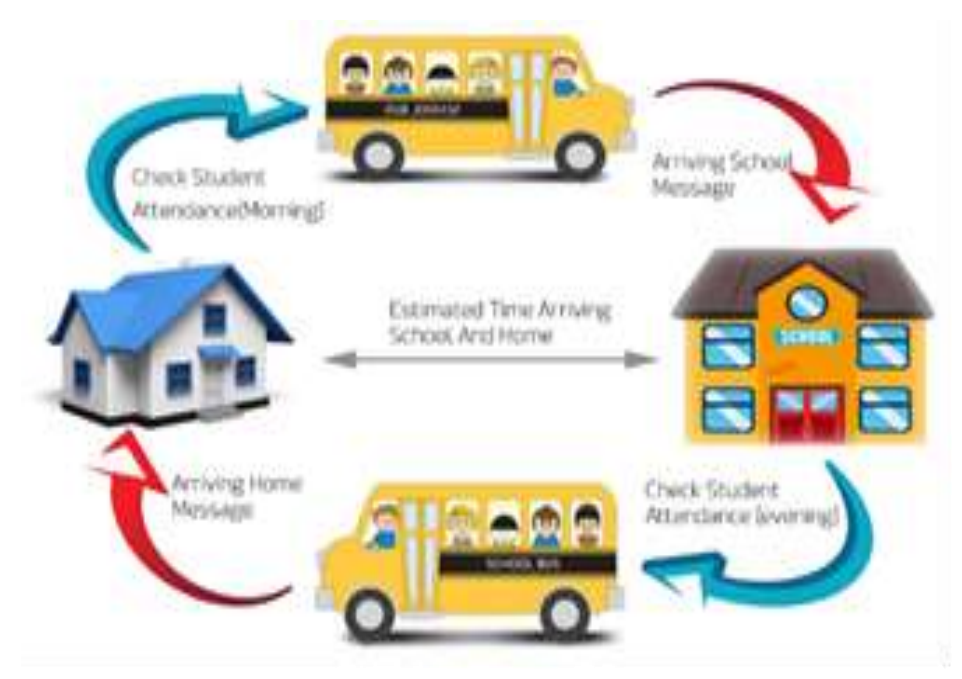

Figure 2. Workflow diagram of school bus security system

\subsection{Flowchart of School Bus Security System}

Flowchart of the designed system to check the attendance of student during morning and evening session is illustrated in Figure 3. On the second part, flowchart of the designed system sending a real-time notification message when the student has safely arrived at the respective location is shown in Figure 4. Referring to Figure 3, after a student scan his/her card at the bus entry door, the student attendance is checked. Otherwise, attendance is 0 . Notification will be sent to parents via SMS. 


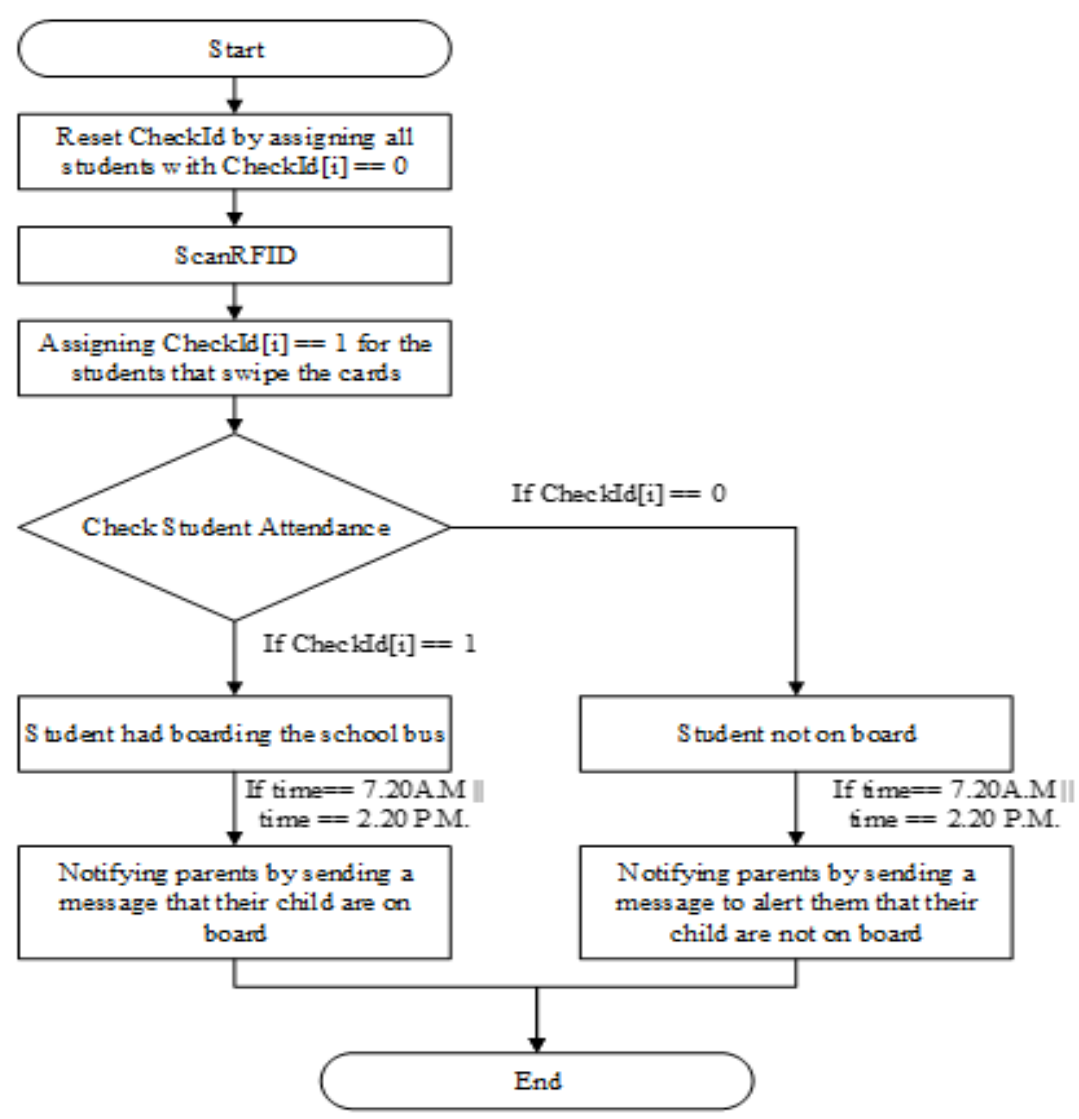

Figure 3. Flowchart of attendance checker

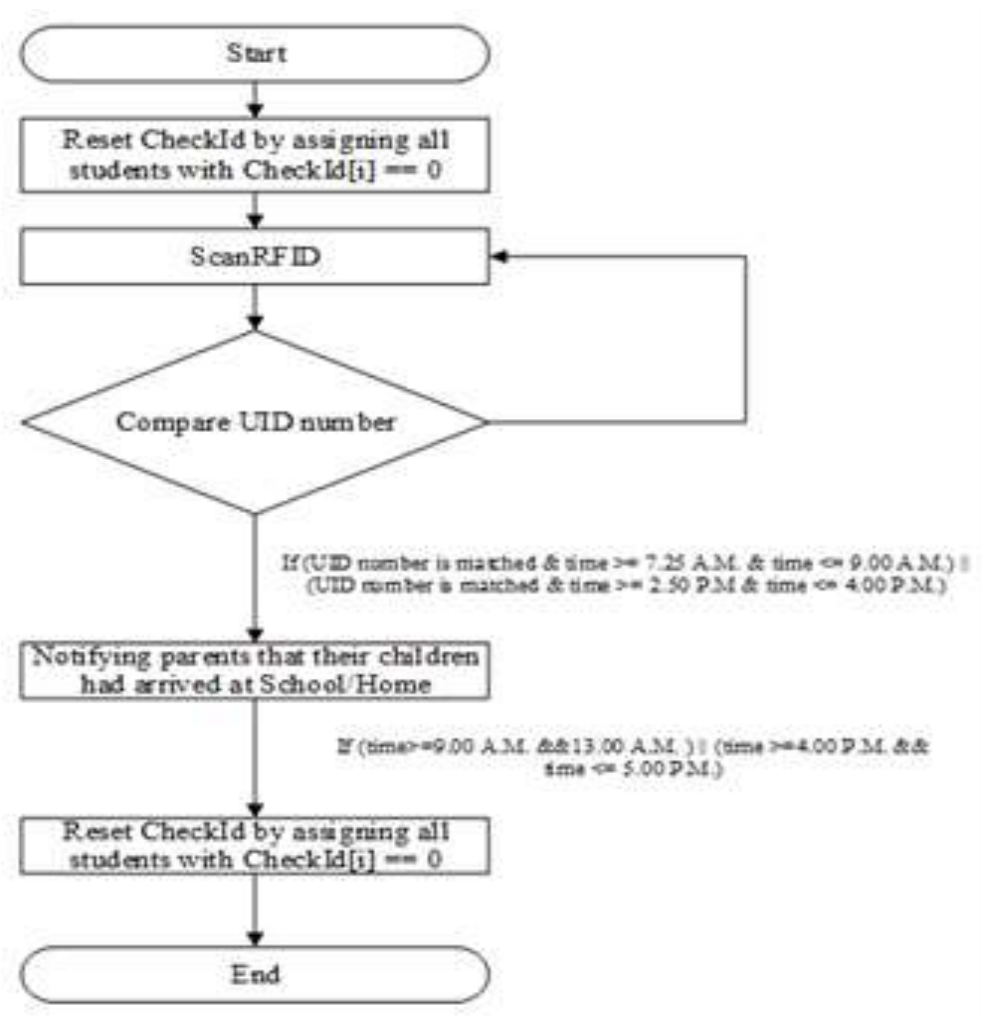

Figure 4. Flowchart of real time notification 


\section{IMPLEMENTATION OF THE PROPOSED SYSTEM}

In this section, hardware and software implementation of the proposed school bus security system are discussed. Figure 5 shows the overall architecture of the system. The hardware components used in this project are shown in Figure 6. Software implementation using Arduino IDE is also discussed.

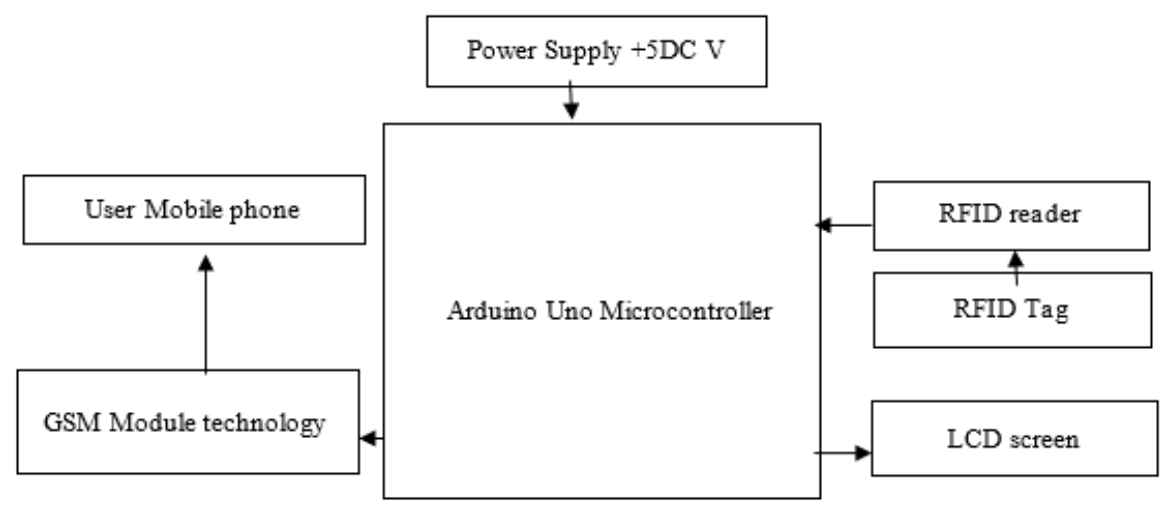

Figure 5. Block diagram of overall design system

The Arduino Uno, as shown in Figure 6(a), has been used as the microcontroller to control the input and output of the system. It operates as a CPU to govern the operation between components. Arduino Uno can be programme and reprogramme easily compared to the other type of microcontroller i.e PIC and ATMEL. This board consists of 32Kbytes of Flash memory and 2Kbytes SRAM [17]. Arduino Uno has been successfully implemented for smart home utilising Internet of Things (IoT) [18-21] and many other applications.

Figure 6(b) shows RC-522 RFID module (reader) with 0 to $10 \mathrm{~mm}$ distance range. The RC-522 RFID tag is defined by a unique ID number that can be read by the RFID reader. The RFID reader and tag communicate through $13.56 \mathrm{MHZ}$ electromagnetic field. Halal Kit identifier also used the same frequency range in its application [9]. The power requirement of RFID RC-522 reader is 3.3V which is connected to Arduino Uno board. The reader is then decode the inquiry signal from the tag and send a respond to the microcontroller.

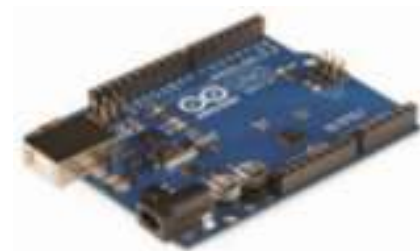

(a) Arduino Uno

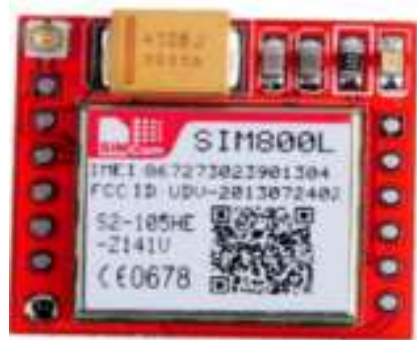

(c) SIM-800L GSM Module

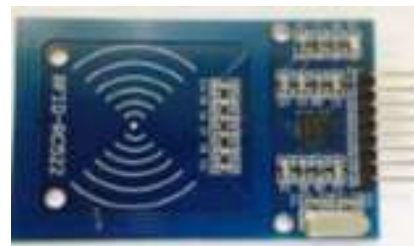

(b) RC-522 RFID Reader Module

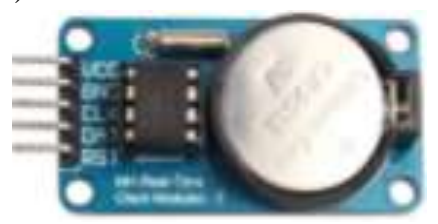

(d) DS-1302 RTC Module

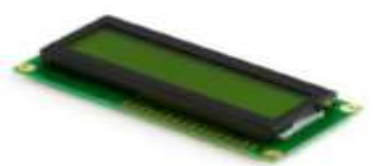

(e) LCD 16x2

Figure 6. Hardware components of the proposed system 
Real Time Clock (DS-1302), as shown in Figure 6(c), is capable to store time and date in single chip circuit. The single chip circuit integrated inside the DS-1302 RTC module is known as Timekeeping chip. This chip is embedded with a Trickle-charger circuitry where the function is to ensure the capacitor can maintain the operation of clock while the power supply is absent [22]. The frequency of RTC oscillator is about $32.768 \mathrm{KHz}$ and having a pull-up resistor up to $2.2 \mathrm{~K} \Omega$. This module has lower power consumtion (about less than $1 \mu \mathrm{W}$ ).

SIM-800L GSM module is a telecommunication device that used to send and receive a message from the user, as shown in Figure 6(c). It acts as mobile phone network when SIM card is inserted. The module has GSM modem and able to operate over the wireless network. This concept has been used to develop low cost digital wireless meter and controlling and monitoring electric feeder [23, 24]. Before using it with Arduino Uno, GSM module needs to be initialized its signal coverage. The suitable operating voltage for this module to send a notification message is about $3.7 \mathrm{~V}$ to $4.2 \mathrm{~V}$.

A 16x2 Liquid Crystal Display (LCD), as shown in Figure 6(e), is used to display the status information of a student either in/out from the school bus. The software part was implemented using Arduino IDE (Integrated Development Environment). The programme codes were developed and deployed to the Arduino board for standalone application.

\section{RESULTS AND DISCUSSION}

Tests have been performed on the developed school bus security system prototyple. The integrated GSM and RFID technologies have been tested as a proof of concept. Some results have been presented in [25].

\subsection{RFID Test}

Students scanned their RFID tag over the RFID reader that is installed at the bus door. Attendance of the students were checked, as shown in the Aduino's serial monitor output shown in Figure 7.

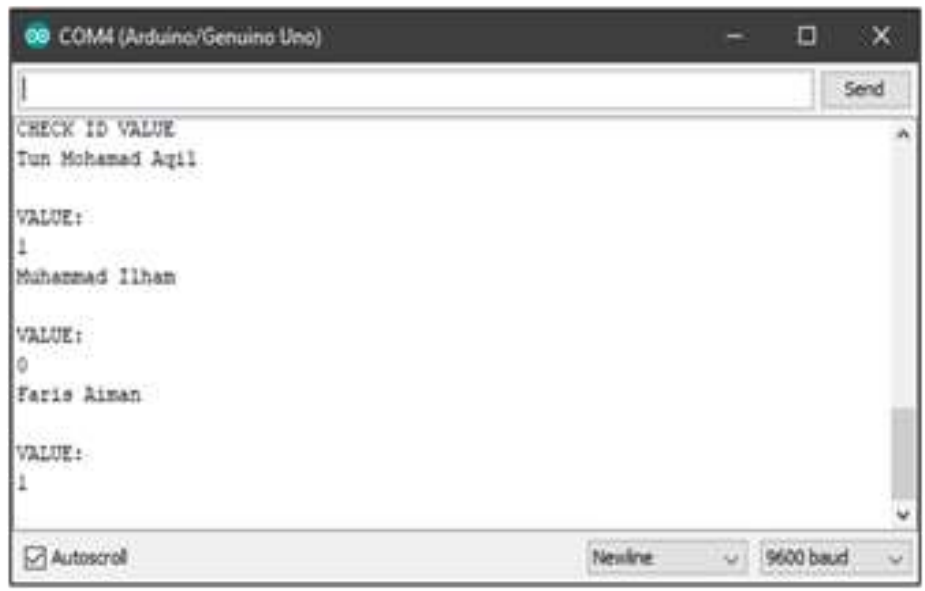

Figure 7. Serial monitor output after scanning operations

A serial monitor of the Arduino IDE displayed information regarding the check ID of the respective students. Initially, the developed school bus security system assigned all the students that have been registered with a check ID equivalent to ' 0 '. When students scanned their RFID tags at the RC-522 RFID reader module, UID number was checked. If the UID number is matched with the registered information system, the value of the check ID will turn into ' 1 '.

The purpose of assigning the check ID value is to indicate the attendance of the students on the school bus. The value of check ID equivalent to ' 0 ' means that the students are absent or not boarding the school bus, while the value of check Id equal to ' 1 ' means the students attend or boarding on the school bus. Figure 7 shows the output from the serial monitor after scanning operation.

\subsection{Overall Performance of Bus Security System}

The overall performance test was conducted where the RFID data was intergrated with the GSM. During the implementation, four different students with unique identification cards was used. The bus

Safety and security solution for school bus through RFID and GSM technologies (Hasmah Mansor) 
security system hardware prototype was connected to $9 \mathrm{~V}$ power adapter/supply to power up and initialised SIM-800L GSM module. Once the system has been activated, the LCD screen displayed the instruction to scan the RFID tag including with the real time clock as shown in Figure 8.

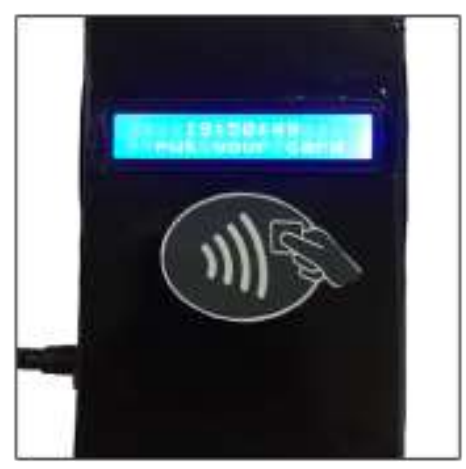

Figure 8. LCD output of attendance checker during morning session

There are four types of pre-defined text output that could be displayed on the LCD screen module as well as in the parents' mobile phone.

OUTPUT 1 (Depart from home): During the morning session, the school bus driver picked up students at their respective houses. The system read the initial timeframe in order to notify the parents either their kids had attended or boarding on the school bus. Figure 9 indicates the output from the LCD module to check the overall attendance of the students during the morning session.

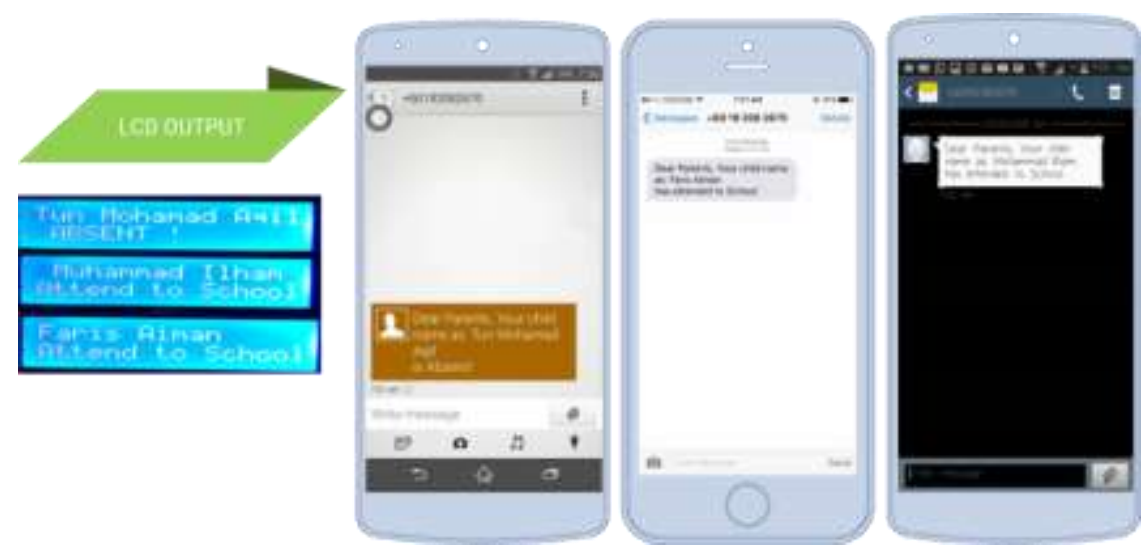

Figure 9. Overall attendance during the morning session

The system checked the overall attendance of the students and sent a notification message to all registered parents in bulk based on the timeframe given. Figure 10 shows the notification message to indicate the attendance of the students during the morning session.

OUTPUT 2 (Arrived at School): As the students leaving the school bus, the LCD screen module printed out the name of each students that have been successfully arrived at the school. Figure 11 shows the output from LCD screen module indicating the students have successfully arrived at the school compound.

Notification messages were directly sent to the parents when the students swiped their cards on the particular RFID reader at the exit door. Figure 12 shows a real time message indicating the students have arrived at the school compound.

Output 3 (Depart from school): In the afternoon, the students were riding the bus again to go back home. The students scanned their RFID tags over the RFID reader located at the school bus. Similar to the morning session mechanism, real time notifications were sent to parents to inform the students have boarded on the school bus, as shown in Figure 13. 
Output 4 (Arrived at Home): When the students reached their respective homes, the students scan the RFID tags over the RFID reader again. A real time message indicating that the particular student has arrived at home is shown at Figure 14.

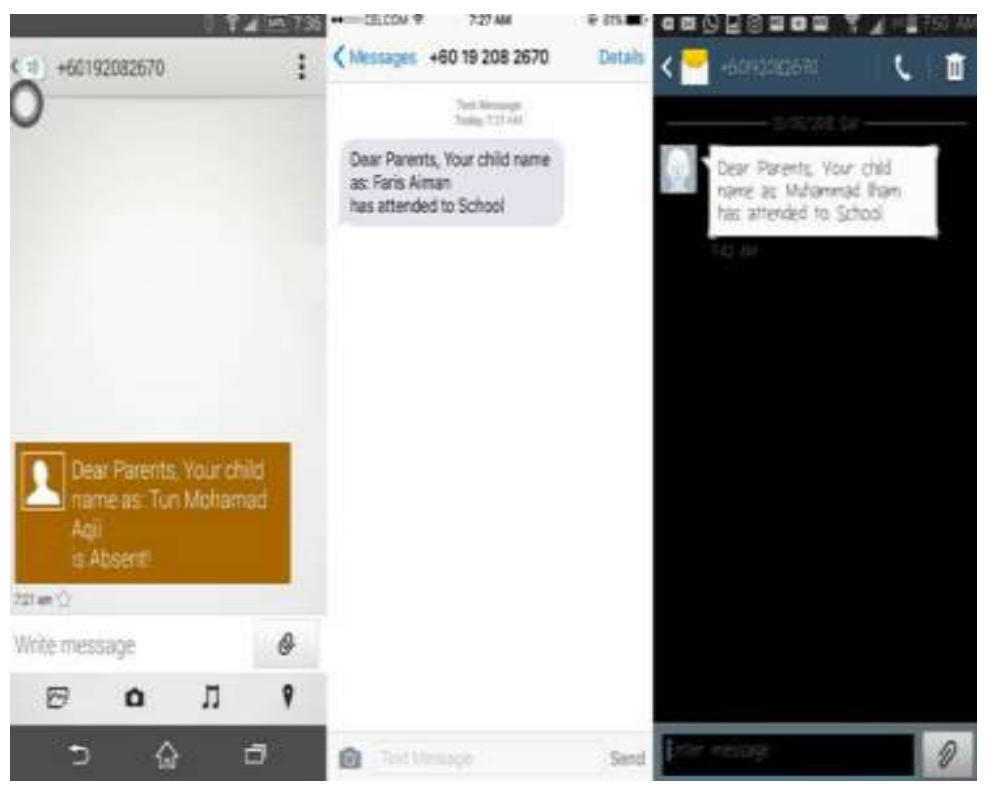

Figure 10. Real time attendance notification to parents

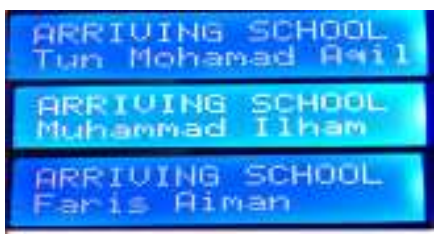

Figure 11. LCD output indicating students arrival at school

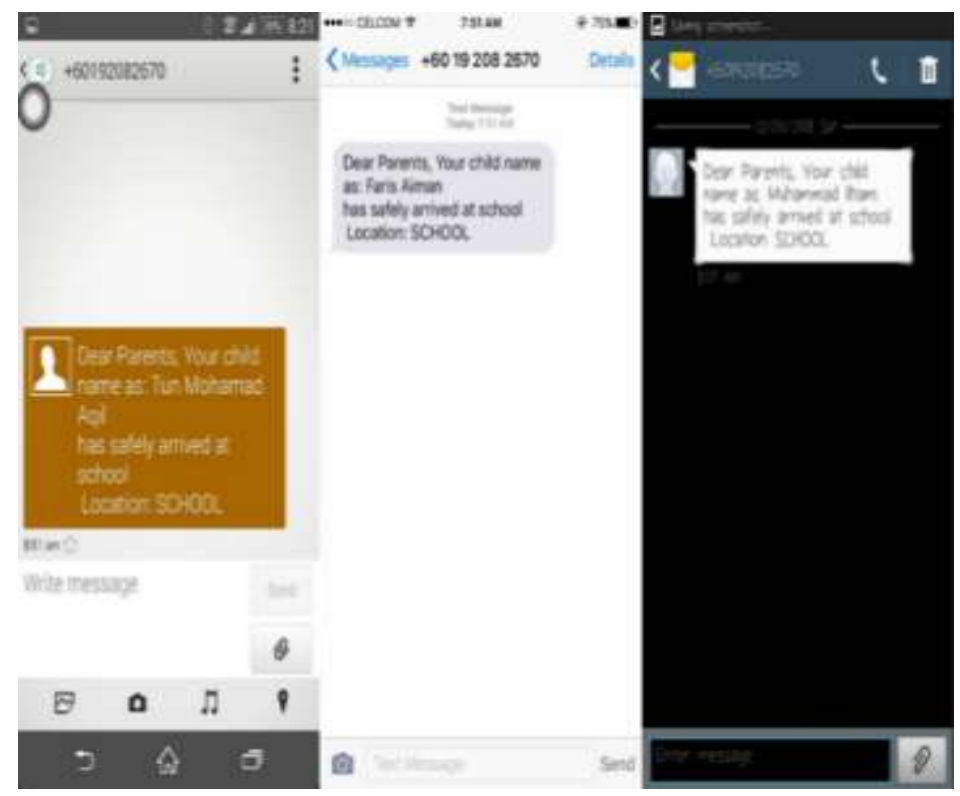

Figure 12. Real time arrival notifications to parents 


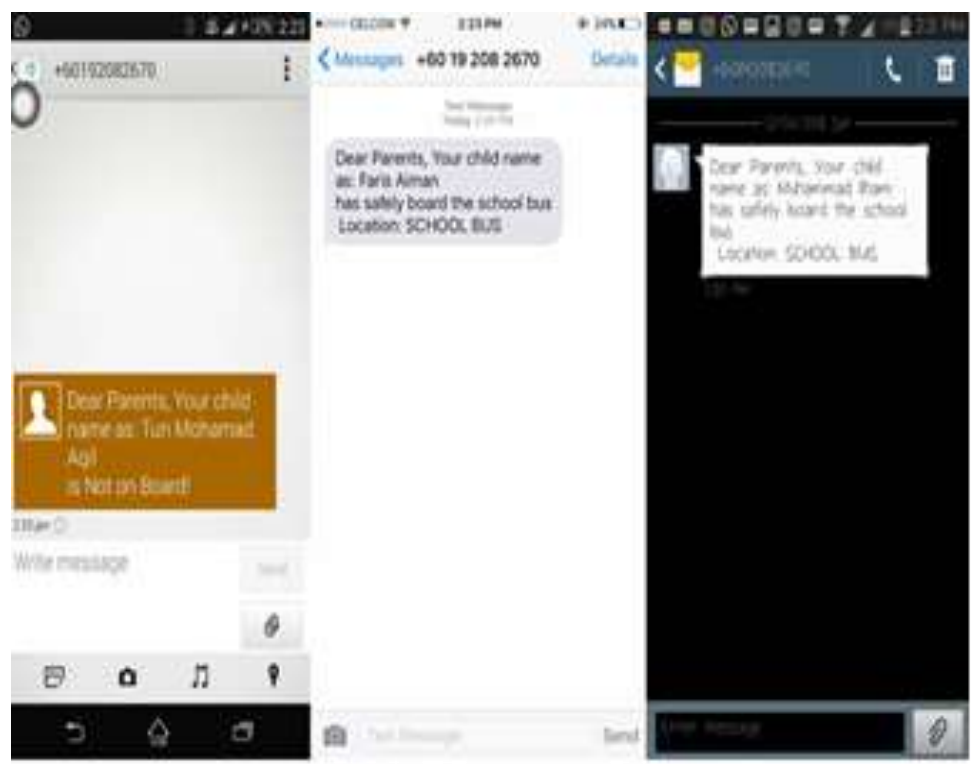

Figure 13. Real time notifications to parent when particular student has boarded on the school bus in the afternoon

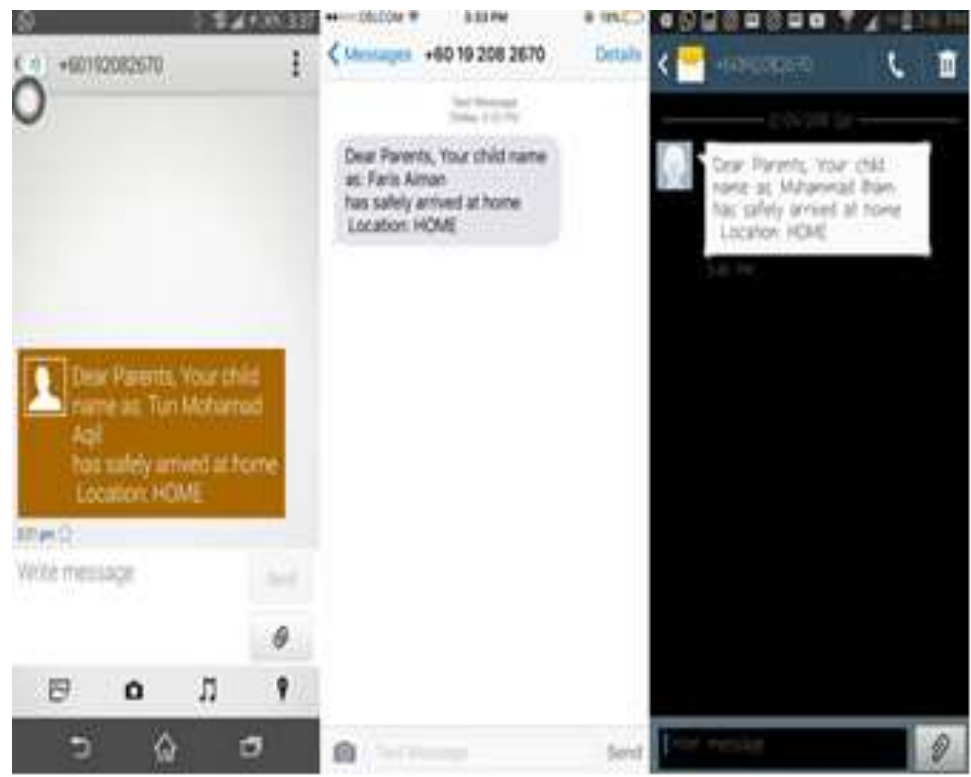

Figure 14. Real time message indicating the particular student has arrived at home

\section{CONCLUSIONS AND FUTURE WORKS}

A school bus with children security system has been successfully developed using RFID and GSM technonologies. Focus was made on Klang Valley area where GSM technology is available and stable; and most working parents are depending on school bus services for their children. The RFID technology has been successfully implemented to detect the student's movement while they were entering or exiting the school buses. Using GSM technology, notification message has been sucesfully sent to parent mobile's phone as soon as their children were successfully departed or arrived at the destination. Attendance checker, as an additional feature has given early notification to the parents if the children are not on board (absent). Implementation of this device and system at all school buses in Malaysia especially in Klang Valley could reduce missing, truancy and kidnap cases among the school children. For improvement, Global Positioning System (GPS) may be proposed for future project as the location tracker instead of using frame mechanism. As another option, wristband type with coil-on chip technology can be used to replace RFID card. 


\section{ACKNOWLEDGEMENTS}

The authors would like to thank International Islamic University Malaysia (IIUM), Universiti Teknologi MARA (UiTM) Shah Alam and University of New South Wales (UNSW) for providing facilities to support the research work.

\section{REFERENCES}

[1] S. Shah and B. Singh, "RFID Based School Bus Tracking and Security System," 2016 IEEE International Conference on Communication and Signal Processing, India, pp. 1481-1485, 2016.

[2] Z. Fang, W. Chen and Y. He, "A RFID based Kindergarten Intelligence Security System," 2012 Ninth IEEE International Conference on e-Business Engineering, China, pp. 321-326, 2012.

[3] P. Surve, B. Ballal, H. Phatak, P. Gade and G. Nirbhavane, "RFID \& GSM Based Child Security System," International Journal of Innovative Research in Electrical, Electronics, Instrumentation and Control Engineering, India, pp. 320-323, 2016.

[4] M.N. Zaki Juhari and H. Mansor, "IIUM Bus On Campus Monitoring System," IEEE Conference Proceedings of the 2016 International Conference on Computer \& Communication Engineering, Kuala Lumpur, pp. 138-143, 2016.

[5] M.T., Kamisan, A.A. Aziz, W.R.W Ahmad and N. Khairudin, "UiTM Campus Bus Tracking System Using Arduino Based and Smartphone Application," 2017 IEEE 15th Student Conference on Research and Development (SCOReD), Malaysia, pp. 137-141, 2017.

[6] Rahman M. M., Mou J. R., Tara K. and Sarkar M. I., "Real Time Google Map and Arduino Based Vehicle Tracking System," International Conference on Electrical, Computer \& Telecommunication Engineering (ICECTE), Bangladesh, pp. 8-10, 2016.

[7] S. Nath, P. Banerjee, R. Nath, S. K. Mitra and Mrinal Kanti Naskar, "Arduino Based Door Unlocking System with Real Time Control," 2016 International Conference on Contemporary Computing and Informatics (IC31), India, pp. 358-362, 2016.

[8] P. Kumar, A. Gupta, K. Nalwa, M. Kumar, A. Bharadwaj and M. Adithya, "Intelligent Multilevel Car Parking System using RFID,” International Journal of Simulation-Systems, Science \& Technology, pp. 14.1- 14.5, 2016.

[9] A. Ibrahim, A. Paravath, P.K. Aswin, S. M. Iqbal and U. S Abdulla, "GSM Based Digital Door Lock Security System," 2015 IEEE International Conference on Power, Instrumentation, Control and Computing (PICC), India, pp. 1-6, 2015.

[10] N. Arbain, N.F. Nordin, N.M. Isa and S. Saaidin, "LAS: Web-based Laboratory Attendance System by integrating RFID-ARDUINO Technology," 2014 IEEE International Conference on Electrical, Electronics and System Engineering, Kuala Lumpur, pp. 89-84, 2014.

[11] N. Hafizah, A. Abd, and H. Mansor, "Halal Kit Identifier using Radio Frequency Identification Technology," 2016 International Conference on Computer and Communication Engineering (ICCCE), Malaysia, pp. 126-131, 2016.

[12] R. Angeles, "RFID Technologies: Supply-Chain Applications and Implementations Issues," IEEE Eng. Manag. Rev., vol. 35, no. 2, pp. 51-66, 2007.

[13] P. Jones, C. Clarke-Hill, D. Comfort, D. Hillier and P. Shears, "Radio frequency identification and food retailing in the UK", British Food Journal, vol. 107, no. 6, pp. 356-360, 2005.

[14] A. Launois, FoodProductionDaily.com, "RFID tracking system stores wine bottle data", 2016. [Online]. Available: http://www.foodproductiondaily.com/news/ng.asp?id=84511. [Accessed: 16- Jan- 2016].

[15] S. Sumi and J. Kumar, "Application of Rfid Technology in Libraries", Proceedings of the $5^{\text {th }}$ International CALIBER-2007, 2007.

[16] H. A. Kadir, M. H. A. Wahab, Z. Tukiran, and A. A. Mutalib, "Tracking Student Movement using Active RFID technologies architecture," Proceedings of the 9th WSEAS International Conference Application Computer Engineering, pp. 41-45, 2010.

[17] D. Brown, RFID implementation. New York: McGraw-Hill, p. 466, 2007

[18] Koprda Stefan, Balogh Zoltan, Hruby Dusan and Turcam Milan, "Proposal of the irrigation system using low-cost Arduino system as part of a smart home," 2015 IEEE 13th International Symposium on Intelligent Systems and Informatics, Serbia, pp. 229-233, 2015.

[19] T.S. Gunawan, I.R.H. Yaldi, M. Kartiwi, N. Ismail, N.F. Za'bah, H. Mansor, and A.N. Nordin, "Prototype design of smart home system using internet of things," Indonesian Journal of Electrical Engineering and Computer Science (IJEECS), vol. 7(1), pp. 107-115, 2017.

[20] A. Pramanik, Rishikesh, V. Nagar, S. Dwivedi, and B. Choudhury, "GSM based Smart Home and Digital Notice Board," 2016 International Conference on Computational Techniques in Information and Communication Technologies (ICCTICT), India, 2016.

[21] K. Stefan, B. Zoltan, H. Dusan, and T. Milan, "Proposal of the irrigation system using low-cost Arduino system as part of a smart home," 2015 IEEE 13th International Symposium on Intelligent Systems and Informatics, Serbia, pp. 229-233, 2015.

[22] V. Bagyaveereswaran, S. Ratnakaran, R. Trivedi and S. Sangeetha, "Design of Low Cost Portable DAQ unit for Microbial Fuel Cells," 2017 International Conference on Innovations in Power and Advanced Computing Technologies [i-PACT2017], India, pp. 1-5, 2017. 
[23] V. Barathkumar, S. M. Irshad, S. Gowtham and R. Geethamani, "Microcontroller based Digital Meter with Alert System using GSM," 2017 International Conference on Intelligent Systems and Control (ISCO), India, pp. 444-448, 2017.

[24] Uddin A. A., Mohammed Shahriar K., Mohammed A. and Mohammad Mahbubur R., "Controlling and Monitoring of Electric Feeders Using GSM Network Technology," 2013 Journal of Electrical and Electronics Engineering, Romania, pp. 5-8, 2013.

[25] T. M. A. M. Fadzir, H. Mansor, T. S. Gunawan, Z. Janin, "Development of School Bus Security System Based on RFID and GSM Technonologies for Klang Valley Area", Proceedings of the $5^{\text {th }}$ IEEE International Conference on Smart Instrumentation, Measurement and Applications (ICSIMA), Songkla, Thailand, 2017.

\section{BIOGRAPHIES OF AUTHORS}

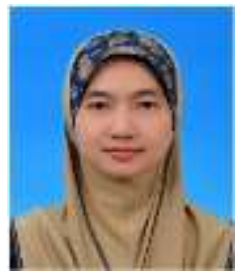

Hasmah Mansor completed her studies at the University of Salford, UK in B.Eng Electronics \& Electrical Engineering with First Class Honours. She has obtained her Master of Science and $\mathrm{PhD}$ in Control and Automation Engineering from Universiti Putra Malaysia. Currently she is an Associate Professor at Electrical and Computer Engineering Department, and starting from Jan 2017 she has been appointed as the Deputy Dean of Students Affairs, Faculty of Engineering, IIUM. She is an IEEE senior member and just been awarded as Chartered Engineer, UK in January 2019. Her research interests include instrumentation and control systems.

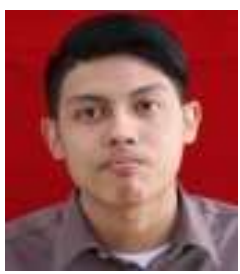

Tun Mohamad Aqil Mohamad Fadzir has completed his B.Eng. (Hons) degree in Communication Engineering, International Islamic University Malaysia (IIUM) in 2018. His research interests are in instrumentation and control.

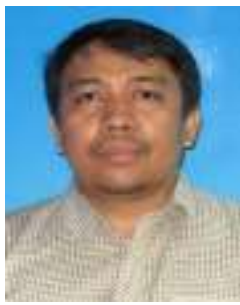

Teddy Surya Gunawan received his B.Eng degree in Electrical Engineering with cum laude award from Institut Teknologi Bandung (ITB), Indonesia in 1998. He obtained his M.Eng degree in 2001 from the School of Computer Engineering at Nanyang Technological University, Singapore, and $\mathrm{PhD}$ degree in 2007 from the School of Electrical Engineering and Telecommunications, The University of New South Wales, Australia. His research interests are in speech and audio processing, biomedical signal processing and instrumentation, image and video processing, and parallel computing. He is currently an IEEE Senior Member (since 2012), was chairman of IEEE Instrumentation and Measurement Society - Malaysia Section (2013 and 2014), Associate Professor (since 2012), Head of Department (2015-2016) at Department of Electrical and Computer Engineering, and Head of Programme Accreditation and Quality Assurance for Faculty of Engineering (2017-2018), International Islamic University Malaysia. $\mathrm{He}$ is Chartered Engineer (IET, UK) and Insinyur Profesional Madya (PII, Indonesia) since 2016, and registered ASEAN engineer since 2018.

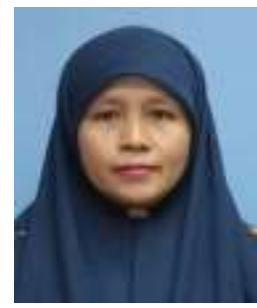

Zuriati Janin received her B. Eng in Electrical Engineering from the Universiti Teknologi Mara, Malaysia in 1996 and MSc. in Remote Sensing \& GIS from the Universiti Putra Malaysia (UPM) in 2001. In 2007, she began her study towards a Ph. D in Instrumentation and Control System at the Universiti Teknologi Mara, Malaysia. She has served as a lecturer at Universiti Teknologi Mara for more than 20 years and currently she is a Senior Lecturer at Faculty of Electrical Engineering, UiTM, Shah Alam. She has been involved with IEEE since 2012 and been mainly working with IEEE Instrumentation \& Measurement Chapter (IM09), Malaysia Section since 2013. The IM09 acknowledged her role as a founder Treasurer in initiating and promoting ICSIMA as a series of annual chapter's flagship conferences since its inception in 2013. She also has more than 10 years experiences in organizing the International Conferences, Workshops and Seminars. Her role as a conference treasurer started since 2005. 